\title{
Uma Avaliação das Críticas de Chomsky ao Verbal Behavior à Luz das Réplicas Behavioristas ${ }^{1}$
}

\author{
Francis Ricardo dos Reis Justi ${ }^{2}$ \\ Universidade Federal de Minas Gerais \\ Saulo de Freitas Araujo \\ Universidade Federal de Juiz de Fora
}

\begin{abstract}
RESUMO - Os cognitivistas têm assumido que as críticas de Chomsky ao Verbal Behavior refutaram definitivamente a proposta skinneriana. No entanto, mesmo com mais de dez anos de atraso, as réplicas behavioristas à resenha de Chomsky começaram a aparecer. O presente trabalho faz uma revisão desse debate tendo como foco o possível caráter definitivo das críticas de Chomsky. A partir deste ponto de vista, conclui-se que nenhuma das críticas de Chomsky ao tratamento skinneriano do comportamento verbal é definitiva. Porém, algumas observações de Chomsky ainda podem oferecer desafios, como a questão da tautologia na lei do condicionamento operante e a crítica ao abandono do conceito de referência.
\end{abstract}

Palavras-chave: Chomsky; Skinner; comportamento verbal.

\section{An Evaluation of Chomsky's Review of Verbal Behavior According to Behaviorists' Replies}

\begin{abstract}
Cognitive psychologists have taken for granted that Chomsky's review of Verbal Behavior presents a refutation of Skinner's theory. However, only ten years after the Chomsky's review, the behaviorists replies to Chomsky started to appear. This work presents a review of this issue focusing on the possible conclusive character of Chomsky's criticisms. On this point of view, none of Chomsky's arguments against Skinner's theory of verbal behavior are conclusive. However, some of Chomsky's criticisms would still posit challenges, as the problem of tautology in operant conditioning's law and the criticism of the dismissing of the reference concept.
\end{abstract}

Key words: Chomsky; Skinner; verbal behavior.

É comum aos historiadores da Psicologia classificar o período compreendido pelos anos de 1950 a 1960 como um período no qual ocorreu uma verdadeira revolução científica no conhecimento psicológico (Gardner, 1996/1985; Schultz \& Schultz, 1996/1985). Esse período teria sido marcado por uma intensa crítica à abordagem behaviorista e um retorno a problemas clássicos da psicologia, como pensamento, consciência e representação mental. Graças a trabalhos de psicólogos talentosos como Karl Lashley e George Miller e ao lingüista Noam Chomsky, a abordagem behaviorista estava sendo duramente criticada ao mesmo tempo em que um novo paradigma para se estudar a mente era proposto. Neste paradigma, a utilização de representações mentais na explicação do comportamento humano era tida como fundamental e o computador digital visto como um modelo essencial para que se entendesse como a mente funciona (Gardner, 1996/1985).

O novo paradigma proposto pela "revolução cognitiva" foi tão influente que o cognitivismo ${ }^{3}$ continua até hoje a ser

1 Os autores agradecem a Carlos Eduardo Lopes pelos valiosos comentários e sugestões relativos a versões preliminares do presente texto. $\mathrm{O}$ autor Francis Ricardo dos Reis Justi desenvolveu a parte final deste trabalho como bolsista do CNPq.

2 Endereço: Rua Francisco Vaz de Magalhães, 600/302 a, Juiz de Fora, MG, Brasil 36033-340. E-mail: francisj@uai.com.br

3 Utilizamos o termo "cognitivismo" em um sentido bastante geral para denotar a utilização de estados e episódios internos na explicação do a abordagem predominante na Psicologia. Parte desta influência se deve ao fato de que até mesmo alguns behavioristas sempre se mostraram céticos quanto à possibilidade de uma explicação adequada do comportamento verbal dentro dos moldes behavioristas e, desse modo, acabavam tornando-se mentalistas disfarçados (MacCorquodale, 1969). Outra parte se deve ao "suposto" fracasso do livro Verbal Behavior de B. F. Skinner, considerado a mais audaciosa e detalhada tentativa behaviorista de explicar o comportamento verbal. De fato, parece existir um entendimento tácito entre os cognitivistas de que as críticas de Chomsky a Skinner refutariam definitivamente o modelo behaviorista para a explicação do comportamento verbal (Chomsky, 1967; Fodor, 1975; Pinker, 1994, 1999). Este fato pode ser notado em um prefácio escrito por Chomsky (1967) a uma reimpressão de sua resenha sobre o livro de Skinner. Neste prefácio, Chomsky argumenta que não vê qualquer maneira pela qual o behaviorismo, o neobehaviorismo ou qualquer idéia empirista pudesse se livrar das críticas que ele fez ao livro de Skinner.

Um outro fator que contribuiu para disseminar essa crença foi um atraso de mais de dez anos para que as réplicas behavioristas à resenha de Chomsky começassem a aparecer, sendo que nenhuma delas foi escrita pelo próprio Skinner.

comportamento, fazendo uso, principalmente, de um nível de análise que utilize representações mentais. Nesse sentido, todo cognitivismo seria mentalista. 
Dentre elas, a mais destacada é a de MacCorquodale (1970), onde este objeta que Chomsky não teria compreendido a especificidade do Behaviorismo Radical de Skinner, confundindo-o com ultrapassadas teorias behavioristas. De fato, MacCorquodale diz que a falta de compreensão de Chomsky sobre a teoria de Skinner é tão grande que as críticas feitas por ele ao Verbal Behavior são inócuas para o livro e para o Behaviorismo Radical.

Outra réplica feita à resenha de Chomsky é a de que essa falha em reconhecer a diferença entre a análise formal, comumente empregada pela lingüística ao analisar uma língua, e a análise funcional, empregada por Skinner ao analisar o comportamento do falante individual (Richelle, 1976). Até mesmo a crítica de Chomsky sobre a inadequação da explicação behaviorista sobre a aprendizagem da gramática tem sido desafiada e alternativas dentro do escopo da teoria skinneriana têm sido apresentadas (Stemmer, 1990).

Surpreendentemente, nenhuma contra-réplica parece ter sido escrita pelos cognitivistas, talvez por acreditarem que de fato Chomsky tenha definitivamente refutado Skinner ou, talvez, pelo fato de que as réplicas apareceram em revistas especializadas em behaviorismo, como Behaviorism e Journal of the Experimental Analysis of Behavior.

As réplicas behavioristas parecem realmente não ter exercido qualquer efeito sobre os modelos teóricos para a explicação da linguagem nas ciências cognitivas. Uma historiadora da lingüística, Julie Andresen (1991), aponta quatro razões para o sucesso das idéias de Chomsky até o início dos anos 80: (1) o gosto por teorias cognitivas; (2) a fundação de paradigmas de pesquisa na tradição simbólica da abordagem de processamento da informação; (3) a força do humanismo; e (4) a tradição textual da disciplina da lingüística. No entanto, de acordo com Andresen (1992), graças ao pensamento pós-estruturalista e às recentes críticas às teorias de Chomsky, a lingüística atual passa por um momento propício à reapreciação do livro Verbal Behavior de Skinner. Ela ainda aponta para a convergência entre o behaviorismo de Skinner e a teorização pós-estruturalista, ressaltando ainda a similaridade entre a teoria de Skinner e as modernas teorias conexionistas sobre o aprendizado da linguagem.

Um outro fato importante a se notar é que o Behaviorismo, embora tenha perdido muito de sua influência, continua até os dias de hoje a orientar pesquisas de maneira bastante ativa. Isso pode ser observado pela existência de jornais especializados em behaviorismo como: Behavior and Philosophy; Journal of Experimental Analysis of Behavior; Journal of Applied Behavior Analysis; The Behavior Analyst; The Analysis of Verbal Behavior. De acordo com de Rose (1994), embora tenham se passado mais de 30 anos da publicação do livro Verbal Behavior, as pesquisas sobre questões relacionadas ao comportamento verbal começam a assumir lugar de destaque na Análise Experimental do Comportamento. Destaque esse que levou pesquisadores brasileiros a analisar a produção científica nacional sobre o comportamento verbal, na tentativa de se identificar pontos de convergência e distanciamento entre as pesquisas nacionais e as estrangeiras sobre esse tópico (Moroz, Rubano, Rodrigues \& Lucci, 2001).

Um fato curioso na pesquisa nacional sobre o comportamento verbal é que, com exceção de um breve comentário de Abib (1994a), não temos qualquer revisão das críticas de
Chomsky ao Verbal Behavior publicada no Brasil. De um ponto de vista histórico, portanto, um trabalho que propusesse tal revisão encontraria justificativa nesta lacuna encontrada na literatura nacional. Além disto, o presente trabalho tornar-se-ia também relevante se, após uma revisão das críticas feitas ao livro, pudesse ajudar a iluminar seus pontos controversos e confusos, facilitando assim a sua compreensão. Uma última justificativa para este trabalho relaciona-se à tendência dos cognitivistas a ignorar a teoria skinneriana do comportamento verbal por acreditar que Chomsky a tenha refutado definitivamente. Essa tendência faz com que a teoria skinneriana, ao invés de ser enxergada como uma teoria rival, seja tratada como uma teoria suplantada, fato que prejudica o debate científico e o progresso das idéias sobre o comportamento verbal.

É em um cenário de crescente interesse e reapreciação do Verbal Behavior por diferentes disciplinas que o presente trabalho encontra o seu maior propósito. Como observamos anteriormente, as críticas de Chomsky parecem ter sido historicamente fundamentais para uma postura negligente quanto ao livro e, apesar dos behavioristas terem apresentado ao longo dos anos algumas contra-críticas a Chomsky, estas nunca foram respondidas. Baseando-nos nesses fatos, o presente trabalho se propõe a fazer uma avaliação desse famoso debate, identificando os pontos específicos da teoria skinneriana criticados por Chomsky, assim como discutir a validade dessas críticas. Além disso, tem-se como objetivo apresentar uma resposta para uma questão que nos parece fundamental neste debate: as críticas de Chomsky invalidariam em princípio, o modelo behaviorista para a explicação da linguagem ou apresentariam falhas desse modelo que poderiam ser superadas sem grandes modificações nas propostas de Skinner?

\section{As Críticas de Chomsky e as Réplicas Behavioristas}

Antes de passarmos à avaliação das críticas de Chomsky, julgamos necessário tratar mais detalhadamente a questão da demora das réplicas behavioristas. Afinal, essa demora tem sido considerada pelos próprios behavioristas uma falha estratégica em seu debate com Chomsky (Abib, 1994a), e, por outro lado, vem sendo utilizada por Chomsky (1967) como um diagnóstico do sucesso de suas críticas.

Em 1967, Chomsky escreveu um prefácio à reimpressão de sua resenha no livro Readings in the Psychology of Language, editado por Jakobovits e Miron. No prefácio, argumentou que, mesmo relendo a resenha oito anos depois, seriam muito poucas as coisas que mudaria nela. Deixou também claro que a resenha tinha um objetivo mais geral:

(...) se eu estivesse escrevendo hoje em dia sobre o mesmo tópico, talvez tentasse deixar mais claro do que deixei, que estava discutindo as propostas de Skinner como um exemplo paradigmático de uma tendência fútil na especulação moderna sobre a linguagem e a mente. (Chomsky, 1967, p. 142)

Chomsky é claramente contra as idéias empiristas na lingüística e parece ter considerado sua resenha não como uma crítica específica da teoria de Skinner, mas das teorias 
behavioristas e empiristas a respeito dos processos mentais de uma maneira geral. De acordo com Chomsky (1967), "o trabalho de Skinner pode ser considerado, com efeito, uma reductio ad absurdum das suposições behavioristas" $(\mathrm{p} .142)^{4}$. Como até esta época nenhuma réplica a sua resenha tinha sido escrita, Chomsky assumiu que suas críticas estavam corretas e que, de fato, refutavam definitivamente a teoria de Skinner e o behaviorismo de uma maneira geral. Como ele mesmo coloca:

Em outras palavras, eu não vejo qualquer maneira pela qual suas propostas possam ser substancialmente melhoradas dentro do escopo geral do behaviorismo ou neobehaviorismo, ou, de maneira mais geral, dentro do escopo das idéias empiristas que têm dominado boa parte da lingüística, psicologia e filosofia. (Chomsky, 1967, p. 142)

No entanto, mesmo com mais de dez anos de atraso, as réplicas behavioristas começaram a aparecer. Mas por que tanta demora e por que nenhuma réplica foi apresentada pelo próprio Skinner? Ele mesmo apresenta duas razões: (1) "em primeiro lugar, eu deveria ter lido a resenha e eu achei o seu tom desagradável. Ela não era uma resenha do meu livro, mas do que Chomsky tomou, erroneamente, por minha posição" (Skinner, 1972, p. 346); (2) "eu também teria que escrutinar a gramática gerativa, o que não era minha área." (Skinner, 1972, p. 346).

Desse modo, Skinner considerou que as críticas de Chomsky (que ele admitiu não ter lido completamente) eram inválidas e que a teoria de Chomsky, ao invés de suplantar e refutar o behaviorismo radical (como esperava Chomsky), apenas rivalizava com este. Esta posição Skinner (1987) sustentou até o fim de seus dias, como podemos ver na passagem abaixo:

Meu Verbal Behavior tem sido chamado de controverso e em um dos sentidos da palavra talvez ele seja, mas boa parte da argumentação nesse sentido é devida a um engano. O livro não é sobre a linguagem.(...) é uma interpretação do comportamento do falante (...) a única questão a se levantar é o quanto essa interpretação é adequada (...). (p. 11 - ênfase dos autores)

Fica claro em Skinner que as razões para não responder à resenha eram que, além de ser escrita em tom desagradável, a mesma em nada tocava a teoria criticada. MacCorquodale (1970) apresenta três razões similares para um atraso na resposta: (1) nem todos os psicólogos da tradição estímulo-resposta eram simpáticos à teoria de Skinner; (2) os skinnerianos, por sua vez, concluíram que as críticas de Chomsky em nada tocavam a teoria que defendiam; (3) o tom desrespeitoso da resenha.

Provavelmente, a única razão que levou os behavioristas a responder a resenha foi a crença dos cognitivistas de que o fato de a resenha não ter sido contra-criticada provava que

4 Esse comentário, além de estar longe de ser justificado, é um indício da má compreensão que Chomsky tem da especificidade da teoria skinneriana em relação aos outros tipos de behaviorismo. Ver os trabalhos de Chiesa (1994) e de Smith (1986) para uma apreciação das diferenças importantes entre os diversos tipos de behaviorismo. ela estava correta. Para avaliar a pertinência das críticas de Chomsky e a adequação das respostas behavioristas, as principais críticas de Chomsky serão apresentadas e contrastadas com as réplicas behavioristas ${ }^{5}$. Para facilitar a exposição, as críticas serão divididas em três subseções: críticas aos conceitos básicos; argumentos baseados na experiência; e críticas ao livro propriamente dito.

\section{Críticas aos conceitos básicos}

Chomsky observou que a proposta de Skinner era a de usar os conceitos básicos desenvolvidos na Análise Experimental do Comportamento para analisar o comportamento verbal. Deste modo, considerou que se atacasse com sucesso esses conceitos, infringiria danos capitais à análise skinneriana do comportamento verbal.

A mais recorrente crítica de Chomsky à proposta de Skinner é a de que este "utiliza resultados experimentais como evidência do caráter científico de sua teoria e suposições analógicas (formuladas em termos de uma extensão metafórica do vocabulário do laboratório) como evidência para o seu alcance" (Chomsky, 1959, p. 30). Basicamente, o que Chomsky critica é que os termos usados na descrição da "vida real" e os usados na descrição dos experimentos de laboratório podem ser meros homônimos, sem qualquer similaridade de significado.

Entendendo-se que a proposta de Skinner era prover uma interpretação do comportamento verbal do falante individual nos termos do Behaviorismo Radical, fica claro que muito da análise empreendida no livro é baseada em suposições analógicas. Mas o que há de errado nisto? Em primeiro lugar, não se pode criticar um autor por aquilo que ele não se propôs a fazer. No seu livro, Skinner deixa claro que este seria muito mais um “(...) exercício de interpretação do que uma extrapolação quantitativa de resultados experimentais rigorosos" (Skinner, 1957, p. 11). De acordo com MacCorquodale (1970), a única coisa que tornaria séria esta objeção seria a possibilidade de que, em princípio, a "vida real" e o comportamento no laboratório seguissem conjuntos de leis diferentes. Porém, se aceitarmos essa possibilidade, somos obrigados a abrir mão de toda a Psicologia Experimental, inclusive de parte da Psicologia Cognitiva, que o próprio Chomsky influenciou (isto para não falarmos da extrapolação de resultados experimentais em outras ciências, como, por exemplo, na Física).

Outra crítica que Chomsky faz a Skinner é a de que os conceitos de estímulo e controle por estímulos (que Chomsky inadvertidamente chama de noções), perderiam toda a sua objetividade fora do contexto do laboratório. Chomsky argumenta que uma pessoa pode emitir um nome próprio, que no caso é considerado uma resposta sob o controle de uma coisa ou pessoa específica, na ausência da pessoa ou coisa. Por exemplo, pode-se dizer "Moscou" sem nunca ter sido estimulado pelo objeto específico, que, neste caso, seria a cidade em si (Chomsky, 1959).

5 Aqui trabalharemos principalmente com a réplica de MacCorquodale (1970) por ser considerada a mais sistemática. No entanto, consideraremos ainda a réplica de Richelle (1976), uma das primeiras no continente europeu. 
Basta notarmos que uma resposta pode estar sob o controle de variáveis diferentes, para rejeitarmos tal crítica. Afinal, uma pessoa pode responder "Moscou" diante da pergunta "qual a capital da Rússia ?", sem que de nenhum modo ela tenha sido estimulada pela cidade em si. Além disso, a pessoa pode dar a mesma resposta "Moscou" em relação a mapas, cartões postais, quadros, entre outros, sem nunca ter ido à cidade. Como MacCorquodale (1970) observa, "o comportamento verbal não obedece qualquer regra do tipo uma resposta - um estímulo" (p. 86).

Dando seqüência às suas críticas, Chosmky nota muito bem a definição de estímulo reforçador dada por Skinner no The Behavior of Organisms (1938):

A operação de reforçamento é definida como a apresentação de um certo tipo de estímulo em uma relação temporal com um estímulo ou com uma resposta. Um estímulo reforçador é definido como tal pelo seu poder de produzir a mudança resultante [aumento na força do operante]. Não existe circularidade a respeito disto; descobrimos que alguns estímulos produzem mudança e outros não, e eles são classificados, por conseguinte, como reforçadores ou não reforçadores. (Skinner, 1938, p. 62)

Baseando-se nesta definição, Chomsky argumenta que esse conceito de estímulo reforçador é “(...) inútil na discussão do comportamento na vida real a menos que possamos de algum modo caracterizar [a priori] os estímulos que são reforçadores (e as situações e condições sob as quais eles são reforçadores)" (Chomsky, 1959, p. 36).

Em uma crítica mais interessante, Chomsky analisa a lei do condicionamento operante proposta por Skinner: "se a ocorrência de um operante for seguida pela apresentação de um estímulo reforçador, a força (desse operante) é aumentada" (Skinner, 1938, p. 21). Feito isso, ele argumenta que a definição skinneriana de estímulo reforçador transforma essa lei em uma tautologia (Chomsky, 1959). Essa crítica nos parece mais importante, pois seria o equivalente a dizer que nenhuma proposição de observação ou um conjunto delas logicamente possível, poderá refutar essa lei de Skinner. Afinal, tal qual a afirmação "todos os solteiros não são casados" a lei do condicionamento operante seria verdadeira por definição e irrefutável.

É importante notar que Chomsky não foi o primeiro a fazer essa crítica. Pelo contrário, ela sempre esteve bastante disseminada não só entre os descontentes com o behaviorismo, mas também entre behavioristas não skinnerianos (Chomsky, 1959; MacCorquodale, 1970). Em resposta a estas críticas MacCorquodale (1970) argumenta que reforçadores podem ser preditos uma vez que eles podem ser "característicos da espécie (os reforçadores incondicionados) ou foram, na história do indivíduo, pareados com um reforçador incondicionado (os reforçadores condicionados)" (p. 87), e que, situações que foram reforçadoras no passado podem ser preditas como sendo reforçadoras no futuro também.

O que soa estranho é que, quando esta réplica de MacCorquodale foi escrita em 1970, Skinner (muito provavelmente) já estava consciente desse tipo de crítica, e mesmo assim continuou defendendo sua definição tradicional de estímulo reforçador, como podemos ver nestas passagens:
“(...) comumente se acredita que reforçadores podem ser identificados a parte de seus efeitos sobre um organismo particular. No entanto, do modo como o termo é usado aqui, a única característica que define um estímulo reforçador é que ele reforça (Skinner, 1953, p. 72). “Diz-se que o comportamento é tornado mais forte por suas conseqüências e por essa razão, essas conseqüiencias são chamadas 'reforçadores', (Skinner, 1974, p. 40).

Até onde sabemos, Skinner parece não ter endossado a resposta de MacCorquodale e, como já observamos, nunca respondeu diretamente às criticas de Chomsky também. Será que a resposta de MacCorquodale é inconsistente com a filosofia da ciência adotada por Skinner? Será que, por princípio, a única definição que Skinner pode prover é a supracitada? Infelizmente, Chomsky não deu seguimento a esse raciocínio nem em sua resenha, nem em trabalhos posteriores. Deste modo, essas questões ficam em aberto, sendo difícil avaliar se essas críticas são definitivas ou podem ser superadas em virtude de algum avanço conceitual.

Podemos observar na subseção atual que Chomsky criticou alguns conceitos básicos da teoria skinneriana como estímulo, estímulo controlador, reforçamento, entre outros. Na seqüência de sua resenha, ele apresenta uma longa crítica das teorias de redução de drive, um conceito que pouco tem a ver com as explicações utilizadas por Skinner no Verbal Behavior e que, por essa razão, não será aqui considerada. Parece que esta longa crítica ao conceito de drive serviu apenas para aumentar a desconfiança dos behavioristas de que Chomsky realmente não compreendeu a teoria skinneriana. Esse fato pode ser observado no comentário de Richelle (1976): “(...) na prolongada introdução de fatos sobre conhecimento latente e exploração, Chomsky parece categorizar Skinner como um teórico da redução de drive. Esse é outro equívoco" (p. 219).

\section{Argumentos baseados na experiência}

Nesta subseção são delineados dois argumentos que Chomsky usa tanto para criticar Skinner quanto para dar suporte à sua própria teoria. No entanto, como o que nos interessa aqui é o comportamento verbal, não adentraremos pelos meandros da gramática gerativa.

O primeiro argumento diz respeito a um "período crítico" para a aprendizagem da linguagem. Chomsky dá o exemplo de uma criança pequena, filha de imigrantes, que aprende uma segunda língua nas ruas, em seus contatos com outras crianças, de maneira muito mais rápida e fluente que seus pais, mesmo que estes estejam extremamente motivados (e necessitados) a aprender a nova língua (Chomsky, 1959).

$\mathrm{O}$ segundo argumento se refere à habilidade que um falante tem de criar e compreender sentenças jamais ouvidas. No caso, ao lermos um simples jornal, nós encontramos uma imensa gama de sentenças que nunca ouvimos anteriormente, mas mesmo assim conseguimos compreendê-las (Chomsky, 1959).

Chomsky considera, então que a teoria skinneriana requer que o comportamento verbal seja estabelecido através de reforço diferenciado extremamente cuidadoso. Baseando-se nesses argumentos e considerações, ele conclui que esses dois exemplos devem ser considerados como uma reductio 
ad absurdum da teoria de Skinner e de teorias similares, uma vez que um processo de reforçamento como esse jamais poderia explicar a rapidez da aquisição da língua pela criança e nem a capacidade de compreensão de sentenças novas do leitor (Chomsky, 1959).

Ao considerar a rapidez com que uma criança adquire seu repertório verbal, Skinner comenta que "uma criança pode aprender a usar uma nova palavra como o efeito de um único reforço, mas aprende-se a fazer coisas não-verbais com velocidade comparável" (Skinner, 1974, p. 103). Deste modo, MacCorquodale (1970) argumentou que é “(...) a dinâmica do processo de reforçamento da criança que é similar à do pombo, e não seus valores de referência" (p. 93). No entanto, é preciso notar que, no caso do filho de imigrantes, esse argumento explica a rapidez e a facilidade da criança para aprender a língua, mas não explica a dificuldade dos pais para aprender essa mesma língua.

Considerando a formação e a "compreensão" de novas sentenças, vejamos, por exemplo, a análise que Skinner faz da conjugação do passado do verbo inglês 'to go'. De acordo com ele, tem-se argumentado que a criança conjuga o tempo passado do verbo 'to go' como 'goed', ao invés da forma correta 'went' (mesmo, provavelmente, nunca tendo ouvido a forma 'goed'). Para Skinner (1974), é possível que o 'ed' da resposta 'goed' seja "(...) um operante separável, como um indicador do tempo passado ou de uma ação completada" (p. 104). Uma vez que a combinação de operantes está dentro do escopo da teoria skinneriana e faz parte de interpretação behaviorista dos comportamentos complexos, não é tão difícil vislumbramos como um behaviorista pode explicar a "compreensão" de novas sentenças através da combinação de operantes diferentes 6 .

Considerando que Chomsky pretendia que seus argumentos pudessem ser considerados uma reductio ad absurdum da teoria skinneriana, fica patente a sua falha. Afinal, não existe nada nesses argumentos que, em princípio, não possa ser explicado pela teoria skinneriana, mesmo que esta explicação possa parecer, à primeira vista, um pouco canhestra e pouco provável.

\section{Críticas específicas ao Verbal Behavior}

Nesta última subseção, serão delineadas as críticas mais específicas que Chomsky faz ao conteúdo do livro Verbal Behavior. De certo modo, quase todas elas dependem em alguma medida das críticas anteriores. Assim, podemos esperar que algumas simplesmente serão mal construídas e equivocadas, enquanto outras serão merecedoras de maior consideração.

Chomsky argumenta que a definição skinneriana de comportamento verbal como o comportamento mediado por outras pessoas, tendo estas pessoas sido condicionadas

6 São especialmente relevantes para esse processo a causação múltipla, onde uma resposta é tornada mais forte pela combinação de duas ou mais variáveis (ver Skinner, 1953, cap. XIV) e, mais especificamente, os diversos tipos de autoclíticos (comportamentos que são evocados por outros comportamentos do falante ou que agem sobre eles). Para maiores considerações sobre o comportamento do ouvinte, que por limitações de espaço não serão tratadas aqui, ver Skinner (1957). precisamente para reforçar o comportamento do falante, não é satisfatória. Ele dá o exemplo de uma pessoa que, ao atravessar uma rua, ouve o grito "olhe o carro!!" e pula, desviando-se do mesmo. Chomsky (1959) argumenta que o comportamento de pular (no caso, a resposta mediadora) dificilmente teria sido condicionada precisamente para reforçar o comportamento do falante (a pessoa que gritou "olhe o carro!!").

Essa crítica só faz algum sentido se nós, equivocadamente, tomarmos o falante da definição de Skinner como uma pessoa específica. Não é difícil imaginar uma situação na história passada do ouvinte em que este, ao ouvir o grito "olhe o carro!!” de sua mãe, foi puxado por ela e posteriormente instruído a prestar atenção. A construção desse repertório na criança (o nosso ouvinte no exemplo) é provavelmente bastante reforçador para a mãe, pois a livra de uma situação aversiva que é ver o seu filho em perigo. Assim sendo, é muito provável que no futuro, ao ouvir esse estímulo verbal em uma situação similar, esse ouvinte vá responder corretamente, sendo o falante sua mãe ou não!!

Para entendermos a próxima crítica de Chomsky é importante considerarmos que, no Verbal Behavior, Skinner propõe diferentes tipos de operantes verbais, como o mando, o tato, o intraverbal, o ecóico, etc. No sistema skinneriano, o que diferencia esses operantes é a sua relação funcional com determinadas variáveis, e não sua topografia. $\mathrm{O}$ mando, por exemplo, é “(...) um operante verbal no qual a resposta é reforçada por uma conseqüência característica e está, dessa maneira, sob o controle funcional de condições relevantes de privação ou estimulação aversiva" (Skinner, 1957, pp. 35-36, ênfase dos autores). Já o tato seria "(...) um operante verbal no qual uma resposta de uma forma dada é evocada (ou pelo menos, tornada mais forte) por um objeto particular, um evento ou uma propriedade de um objeto ou evento" (p. 82). Desse modo, a resposta "água" pode ser um mando (quando emitida por um homem sedento) ou pode também ser um tato (quando emitida por alguém que simplesmente vê a água).

O problema que Chomsky parece identificar nessa proposta é que, por razões éticas, é geralmente impossível se determinar em que condição de privação ou estimulação aversiva uma pessoa está em um determinado momento e que, deste modo, contrariamente ao que Skinner queria, nós tenderemos a identificar uma resposta como mando pela forma e não pelas condições de privação relevantes (Chomsky, 1959). Novamente, o que Chomsky faz é apontar uma dificuldade epistemológica para se testar a teoria de Skinner na "vida real". Nesse sentido, MacCorquodale (1970) responde que "(...) desde que as circunstâncias motivacionais do falante são objetivamente mensuráveis, elas podem, em princípio, ser conhecidas" (p. 96). Embora Skinner enfatize a história do organismo relacionada a uma determinada privação, isso não exclui a possibilidade de que algumas variáveis um pouco mais indiretas possam ser utilizadas como indícios do atual estado de privação do organismo. Ele próprio nos dá um exemplo: "ao estudar um comportamento que é caracteristicamente reforçado com comida nós devemos ter um registro da história de ingestão ou alguma medida contemporânea, como peso corporal, que varie de acordo com esta história" (Skinner, 1953, p. 158). 
Chomsky considera também a explicação oferecida por Skinner da resposta emitida por uma pessoa a um estímulo verbal. O exemplo é o seguinte: em uma caçada, um ouvinte $B$ ouve o falante $A$ emitir a resposta verbal "raposa!!" e reage (apropriadamente) olhando ao redor e preparando seu rifle. Como explicar o comportamento de $B$ ? Chomsky (1959) delineia (corretamente) a explicação de Skinner da seguinte maneira:

\begin{abstract}
Nós assumimos (1) que na história de B o estímulo "raposa" tem sido uma ocasião na qual olhar ao redor tem sido seguido pela visão de uma raposa e (2) que o ouvinte tem algum interesse atual em ver raposas - que o comportamento que dependa da visão de raposas para a sua execução éforte, e que o estímulo suprido por uma raposa é, desse modo, reforçador. B executa o comportamento apropriado, então, porque ouvir o estímulo "raposa" é uma ocasião na qual olhar ao redor é freqüentemente seguida pelo reforçamento de ver uma raposa, $i$. e., seu comportamento é um operante discriminado. (p. 48)
\end{abstract}

Chomsky argumenta que essa explicação não é convincente, posto que o ouvinte $(B)$ pode nunca ter visto uma raposa ou ainda não ter qualquer interesse em vê-la, e mesmo assim poderia reagir apropriadamente ao estímulo "raposa". A essa crítica, os behavioristas poderiam responder com uma pergunta: será que sem uma história de reforçamento, que estabelecesse o estímulo "raposa" como um estímulo discriminativo para o comportamento de olhar ao redor, o ouvinte realmente reagiria apropriadamente ao estímulo "raposa"? O que parece estar em disputa aqui é a idéia geral de que as palavras se referem a coisas (a referência na teoria semântica). A proposta de Skinner é a de dispensar o conceito de referência (Skinner, 1957; Abib, 1994b). Chomsky parece considerar essa proposta contra-intuitiva e problemática, pois crê que diante do estímulo "raposa", o ouvinte pode "compreender" a que se refere a palavra e reagir apropriadamente, sem que tenha tido uma história de reforçamento como a proposta no exemplo anterior. No entanto, ele não demonstra como, nesse caso, a proposta de Skinner seria inconsistente, isto é, como, em princípio, este comportamento não poderia ser explicado pela proposta de Skinner ou como esta suposta explicação implicaria no uso do conceito que Skinner quer dispensar.

Chomsky parece estar querendo sustentar que, em uma situação nova para o ouvinte, a proposta de Skinner ou seria incapaz de explicar o comportamento do ouvinte ou implicaria no uso implícito do conceito de referência. Isto obrigaria Chomsky a analisar pormenorizadamente a construção de novos comportamentos do ouvinte através do uso de instruções (principalmente a análise proposta por Skinner, 1957), o que ele não fez. Estender a discussão deste tópico da obra de Skinner iria não só além do que Chomsky fez em sua resenha, mas também muito além dos objetivos do presente trabalho. De qualquer modo, é importante ressaltar que mesmo pesquisadores simpáticos ao behaviorismo radical, ao considerarem o comportamento do ouvinte, têm observado que a análise deste tipo de comportamento implicaria no uso do conceito de referência (Parrott, 1987).

Uma outra crítica que Chomsky faz a Skinner concerne à análise deste da extensão metafórica (quando propriedades pouco convencionais dos estímulos controlam uma resposta). Por exemplo, ao explicar a resposta verbal emitida por Romeu, "Julieta é como o Sol", Skinner argumenta que Julieta e o Sol "têm propriedades em comum pelo menos no que diz respeito a seu efeito sobre o falante" (Skinner, 1957, p. 93). Chomsky argumenta que é sempre possível achar propriedades em comum entre dois objetos quaisquer e, portanto, é sempre possível explicar uma resposta que diga $A$ é como $B$ apelando para o conceito skinneriano de extensão metafórica (Chomsky, 1959).

A última crítica que Chomsky apresenta relaciona-se com o comportamento autoclítico e o tratamento sugerido por Skinner à gramática e à sintaxe. É provável que estas tenham sido historicamente as críticas de Chomsky mais influentes, pois, por um lado, MacCorquodale não as respondeu e, por outro, o estudo da construção de sentenças gramaticais era o "ponto forte" da teoria chomskyana (Stemmer, 1990). Chomsky (1959) interpreta a proposta de Skinner da seguinte maneira:

(1) “(...) em geral, substantivos são evocados por objetos, verbos por ações, e assim sucessivamente. Skinner considera uma sentença como sendo um conjunto de respostas-chaves (substantivos, verbos, adjetivos) em uma moldura esqueleto" (p. 53);

(2) “(...) os autoclíticos (incluindo a ordem) que qualificam essas respostas expressam relações entre elas (...) são então adicionados por um processo chamado 'composição', e o resultado é uma sentença gramatical (...)” (p. $54)$;

(3) "[no processo de composição] os substantivos, verbos e adjetivos, são escolhidos primeiro e depois são ordenados, qualificados, etc., por respostas autoclíticas a estas atividades internas" (p. 54);

A crítica de Chomsky (1959) é a de que sentenças como “(...) 'sheep provide wool' não têm moldura (física) alguma, mas nenhuma outra disposição dessas palavras é uma sentença da língua inglesa" (p.54). Ainda nesta mesma linha de pensamento, argumenta que "(...) as seqüências 'furiously sleep ideas green colorless' e 'friendly young dogs seem harmless' têm a mesma moldura, mas apenas uma é uma sentença da língua inglesa ...)" (p. 54). Uma vez que inserir palavras em molduras, mesmo que ordenadamente, não garante a produção de sentenças válidas, Chomsky (1959) argumenta que qualquer abordagem da linguagem que falhe em considerar esse fato não pode obter grande sucesso na explicação do comportamento lingüístico.

Primeiramente, a interpretação de Chomsky (1959) de que o tratamento skinneriano do comportamento verbal gramatical se dá pela inserção de "(...) um conjunto de respostas chave (substantivos, verbos, adjetivos) em uma moldura esqueleto" (p. 53), é equivocada. Ironicamente, exatamente na mesma página em que Chomsky encontrou a expressão "moldura esqueleto", Skinner (1957) diz:

Algumas sentenças são mais do que meras respostas-chaves em molduras esqueletos, ou respostas fragmentárias completadas sob pressão para a construção de unidades totais. Um conjunto de variáveis pode ser tão incomum ou tão complexo que o comportamento verbal passado do falante não produz nenhum modelo padrão apropriado. Ele deve, então, manipular suas 
respostas com a ajuda de autoclíticos especiais. A conseqüente criação de segmentos mais amplos de comportamento verbal é uma atividade que pode ser chamada de composição. (p. 346, ênfase dos autores)

É exatamente quando o comportamento não pode ser explicado por molduras que o processo de composição toma lugar e não o contrário. A "criação" de comportamento verbal complexo de modo algum é explicada por Skinner como a seleção de um substantivo, um verbo e um adjetivo em uma moldura esqueleto, ou qualquer coisa similar. $\mathrm{Na}$ verdade, Skinner (1957) é muito claro em dizer que a atividade de composição acontece apenas em ocasiões genuinamente novas e que "(...) muitas instâncias do comportamento verbal que contém autoclíticos gramaticais ou sintáticos podem não representar verdadeira atividade autoclítica" (p. 343). Curiosamente, a causação múltipla, que Skinner considera crucial para a explicação de diversos fatos do comportamento verbal, em nenhum momento é citada por Chomsky na sua resenha, como bem notou MacCorquodale (1970). Desse modo, diante da interpretação errônea por parte de Chomsky desse ponto da proposta skinneriana, suas críticas a ela se tornam inócuas?

\section{Conclusão}

Após ter considerado a maioria das críticas de Chomsky e ter comparado-as com as réplicas behavioristas, é chegado o momento de retornarmos à nossa questão principal: as críticas de Chomsky invalidariam, em princípio, o modelo behaviorista para a explicação da linguagem ou apresentariam falhas desse modelo que poderiam ser superadas sem grandes modificações nas propostas de Skinner?

No que concerne à proposta de Chomsky de refutar definitivamente a teoria de Skinner e similares, podemos concluir que Chomsky de maneira alguma atinge este objetivo. Em primeiro lugar, porque a especificidade da teoria skinneriana impediria qualquer tipo de "refutação geral" do behaviorismo ou empirismo. Em segundo lugar, ao considerarmos as críticas que Chomsky apresentou em sua resenha, podemos notar, à luz das réplicas e do presente trabalho, que quase a totalidade destas críticas estão fundamentadas em equívocos cometidos por Chomsky ao interpretar as propostas de Skinner. Deste modo, poderíamos concluir que de maneira alguma Chomsky refutou definitivamente a teoria skinneriana.

No entanto, algumas dessas críticas podem nos levar a preocupações metodológicas legítimas relativas à testabilidade da teoria de Skinner em condições ecológicas mais significativas. Se melhor articuladas, certas observações de Chomsky parecem apontar dificuldades mais desafiadoras à proposta de Skinner do que as que ele próprio levantou, como por exemplo, a questão da tautologia na lei do condicionamento operante e, talvez, a proposta skinneriana de abandono do conceito de referência. Porém, o tratamento

7 Aqui discutimos apenas as críticas que Chomsky formulou em sua resenha. Para uma discussão mais detalhada das críticas de Chomsky, apresentadas ao longo dos anos, às explicações "empiristas" da construção de sentenças, e também para uma resposta alternativa a aqui proposta, ver Stemmer (1990). desses assuntos exigiria um detalhamento que foge ao propósito do presente artigo. De qualquer forma, é uma investigação que deve ser realizada no futuro. Ao contrário do que os cognitivistas normalmente pensam, o assunto ainda não está encerrado.

\section{Referências}

Abib, J. A. D. (1994a). A atualidade do livro Verbal behavior de B. F. Skinner: um comentário. Psicologia: Teoria e Pesquisa, 10(3), 467-472.

Abib, J. A. D. (1994b). O contextualismo do comportamento verbal: A teoria skinneriana do significado e sua crítica ao conceito de referência. Psicologia: Teoria e Pesquisa, 10(3), 473-487.

Andresen, J. (1991). Skinner and Chomsky 30 years later or: The return of the repressed. Behavior Analyst, 14(1), 49-60.

Andresen, J. (1992). The behaviorist turn in recent theories of language. Behavior and Philosophy, 20(1), 1-19.

Chiesa, M. (1994). Radical behaviorism: The philosophy and the science. Boston, MA: Authors Cooperative.

Chomsky, N. (1959). A review of B. F. Skinner's Verbal Behavior. Language, 35(1), 26-58.

Chomsky, N. (1967). Preface to the 1967 reprint of "A review of B. F. Skinner's Verbal Behavior”. Em L. A. Jakobovits \& M. S. Miron (Orgs.), Readings in the Psychology of language (pp.142143). Englewood Cliffs: N. J.: Prentice-Hall.

de Rose, J. C. (1994). O livro Verbal behavior de Skinner e a pesquisa empírica sobre comportamento verbal. Psicologia: Teoria e Pesquisa, 10(3), 495-510.

Fodor, J. A. (1975). The language of thought. New York: Thomas Y. Crowell.

Gardner, H. (1996). A nova ciência da mente: Uma história da revolução cognitiva. (C. M. Caon, Trad.) São Paulo: EDUSP (Trabalho original publicado em 1985).

MacCorquodale, K. (1969). B. F. Skinner's Verbal Behavior: A retrospective appreciation. Journal of the Experimental Analysis of Behavior, 12(5), 831-841.

MacCorquodale, K. (1970). On Chomsky's review of Skinner's Verbal Behavior. Journal of the Experimental Analysis of Behavior, 13(1), 83-99.

Moroz, M., Rubano, D., Rodrigues, M. \& Lucci, M. (2001). Comportamento verbal - Análise de produção científica nacional publicada no quinqüênio 1994-1998. Revista Brasileira de Terapia Comportamental e Cognitiva, 3(1), 69-82.

Parrott, L. J. (1987). Rule-governed behavior: An implicit analysis of reference? Em S. Mogdil \& C. Modgil (Orgs.), B. F. Skinner: Consensus and controversy (pp. 265-276). New York: Taylor \& Francis.

Pinker, S. (1994). The language instinct. New York: Harper-Collins Publishers.

Pinker, S. (1999). Words and rules. New York: Harper-Collins Publishers.

Richelle, M. (1976). Formal analysis and functional analysis of verbal behavior: Notes on the debate between Chomsky and Skinner. Behaviorism, 4(2), 209-221.

Schultz, D. \& Schultz, S. (1996). História da psicologia moderna. (A. U. Sobral \& M. S. Gonçalves, Trads.) São Paulo: Cultrix (Trabalho original publicado em 1985).

Skinner, B. F. (1938). The behavior of organisms. New York: Appleton-Century-Crofts. 
Skinner, B. F. (1953). Science and human behavior. New York: The Free Press.

Skinner, B. F. (1957). Verbal behavior. New York: AppletonCentury-Crofts.

Skinner, B. F. (1972). A lecture on "having" a poem. Em B. F. Skinner (Org.), Cumulative Record: A selection of papers (pp. 345-355). New York: Alfred A. Knopf.

Skinner, B. F. (1974). About the behaviorism. New York: Alfred A. Knopf.
Skinner, B. F. (1987). Reflections: Controversy? Em S. Mogdil \& C. Modgil (Orgs.), B. F. Skinner: Consensus and controversy (pp. 11-12). New York: Taylor \& Francis.

Smith, D. (1986). Behaviorism and logical positivism: A reassessment of the alliance. Stanford: Stanford University Press.

Stemmer, N. (1990). Skinner's Verbal Behavior, Chomsky's review, and mentalism. Journal of the Experimental Analysis of Behavior, 54(3), 307-315.

Recebido em 30.09.2003

Primeira decisão editorial em 02.04.2004

Versão final em 13.08.2004

Aceito em 27.08.2004 